\title{
Models of Transportation and Land Use Change: A Guide to the Territory
}

\section{Michael Iacono \\ David Levinson \\ Ahmed El-Geneidy}

Modern urban regions are highly complex entities. Despite the difficulty of modeling every relevant aspect of an urban region, researchers have produced a rich variety of models dealing with interrelated processes of urban change. The most popular types of models have been those dealing with the relationship between transportation network growth and changes in land use and the location of economic activity, embodied in the concept of accessibility. This article reviews some of the more common frameworks for modeling transportation and land use change, illustrating each with some examples of operational models that have been applied to real-world settings. It then identifies new directions for future research in urban modeling and notes the important contributions of the field to date.

Keywords: transportation planning; land use; mathematical models; urban growth; gravity model; microsimulation

\section{INTRODUCTION}

Models are the basic tool of analysis for planners working in the fields of transportation and land use forecasting. Current practice in these fields generally accepts the notion of some type of reciprocal relationship between transportation and land use. For more than four decades, urban researchers have sought to formalize this relationship using mathematical, statistical, and logical methods, and to produce models capable of predicting changes to transportation and land use systems as the result of policy measures.
This article reviews some of the important theoretical frameworks adopted by researchers to represent the complex relationship between transportation and land

Michael IACONO is a research fellow in the Department of Civil Engineering at the University of Minnesota-Twin Cities. His research interests include transportation planning, policy and economics, and urban policy and economics. He is currently conducting research on multimodal measures of accessibility and models of land use change for the Twin Cities Metropolitan Region.

DAVID LEVINSON is an associate professor in the Department of Civil Engineering at the University of Minnesota and director of the Networks, Economics and Urban System (NEXUS) research group. In academic year 2006-2007 he was a visiting academic at Imperial College in London examining the coevolution of transport and land use. He currently holds the Richard P. Braun/CTS Chair in Transportation Engineering.

AhMED EL-GeNeIDY is an assistant professor at the School of Urban Planning, McGill University. His research interests include land use and transportation planning, transit planning and operations, and accessibility/mobility measures for urban areas. He earned $B S$ and MS degrees from the Department of Architectural Engineering at the University of Alexandria, Egypt, and continued his academic work at Portland State University, where he received a Graduate GIS Certificate and earned a PhD in Urban Studies.

The authors would like to acknowledge the comments of two anonymous reviewers who helped to correct and clarify a number of key ideas developed in this article. This research was undertaken as part of the project Access to Destinations: Monitoring Land Use Activity Changes in the Twin Cities Metropolitan Region, administered and supported by the Minnesota Department of Transportation.

Journal of Planning Literature, Vol. XX, No. X (Month XXXX) DOI: $10.1177 / 0885412207314010$

Copyright (c) 2008 by Sage Publications 
use. Each framework has guided the development of a number of different operational models, that is, models that have been applied using data from real-world metropolitan regions. Several of these models are described in some detail to illustrate how each modeling framework is used to represent the processes of urban change. ${ }^{1}$ Before turning to the models, however, some background is provided on the transportation-land use relationship and the chronological development of transportation and land use modeling.

The first two modeling frameworks to be discussed are those based on aggregate models of spatial interaction and econometric models. These two modeling frameworks provide the vast majority of current operational models that are used in planning practice. We might refer to these first two frameworks as "topdown" modeling frameworks, since they specify the interaction between transportation networks and location as a set of aggregate relationships based on the behavior of a representative individual, usually the mean calculated from a representative sample of the population. The third class of models to be introduced falls under the general category of microsimulation models. These models cover a number of different approaches to representing the dynamics of land use change and travel behavior, but generally share the common focus of attempting to disaggregate the population and to simulate changes from the "bottom up," redefining the nature of actors in the model. Models of activity-based travel are discussed here, along with multi-agent models and cell-based models, a special type of multi-agent model that offers an alternative mechanism for representing the dynamics of land use change. Some examples of prototype urban models that are being developed entirely within a microsimulation framework are described.

The later sections of the article review some of the common criticisms directed toward land use and transportation models and note how these criticisms have (or have not) been addressed in the most recent generation of models. Some outstanding issues are discussed and suggestions offered as to important future research directions. A concluding section follows with some general remarks on the state of transportation and land use modeling and its relationship to planning as a discipline.

\section{THE TRANSPORTATION-LAND USE RELATIONSHIP}

Transportation networks and the spatial patterns of land use they serve are assumed to mutually influence each other over time. Changes to transportation networks, such as the construction of a new link or expansion of an existing one, eventually influence the location of investment in land, which in turn influences the demand for travel to and from a particular location. This relationship is sometimes referred to as the transportation-land use "link" or "cycle," emphasizing a feedback relationship (Kelly 1994). The mediating factor in determining changes in the location of activities and the demand for travel is accessibility, which measures the situation of a location relative to other activities or opportunities (work, shopping, etc.) distributed in space. Changes in relative accessibility are measured indirectly when researchers attempt to identify the influence of new infrastructure, such as a highway link or transit station, on local land markets. In these cases, accessibility is usually approximated by some measure of access to the transportation network, such as travel time or distance (Ryan 1999). Generally, the degree of land market impact is related to the impact of the new transportation link on regional accessibility, and so is roughly proportional to the increase in speeds (and reduction in travel time) permitted by the new link (Cervero 1984).

To operationalize the transportation-land use relationship within models of transportation and land use, measures of accessibility are incorporated in determining the location of activities. It is typically assumed that households wish to locate in areas with higher accessibilities to opportunities such as employment or shopping, while firms are assumed to locate in areas with higher accessibility to labor markets, perhaps stratified by occupational type. In models where land and floor space markets are considered explicitly, these accessibility factors can be important determinants of price. Since most models of transportation and land use contain a land use component that is integrated with, or at least loosely coupled with, a travel demand model containing a network assignment component, congested network travel times can be fed into the calculation of accessibility, thus providing a measure of the impact of congestion on regional accessibility and activity location.

To simulate these changes within models of metropolitan regions, the region is typically broken down into a set of small geographic zones, similar (or in many cases identical) to the set of zones used for regional travel forecasting. Accessibility is typically calculated from each zone to all other zones in the region via the regional transportation network. Changes to the travel network that alter zone-to-zone travel times thus impact the relative accessibility of a location.

\section{CHRONOLOGY OF MODEL DEVELOPMENT}

The history of simulation models of transportation and land use dates to the late 1950s (Batty 1979). While models of regional travel demand had been established 


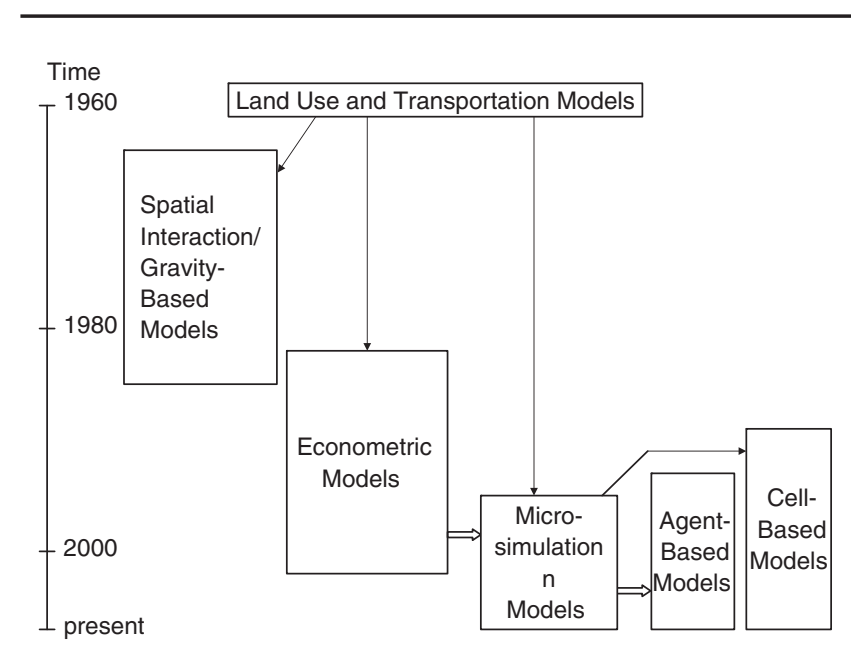

FIGURE 1. Chronological Development of Land Use and Transportation Models

as far back as the early 1950s and some early experiments with transportation and land use models were carried out in the following years, it was not until the early 1960s that the first operational land use simulation model was built. The "Model of Metropolis" developed by Lowry (1964) is widely considered to be the first operational simulation model of urban land use. Lowry's model was the first of a generation of models based on theories of spatial interaction, including the gravity model that was popular in quantitative geography at the time. Models based on a spatial interaction framework continued to be developed through the early to mid-1980s, when they became largely replaced by models grounded in random utility theory and econometric methods.

Figure 1 describes this process and gives an approximate timeline for the adoption of various modeling frameworks within transportation and land use research. Several of the models that follow an econometric framework continue to be used today, although some, like the UrbanSim simulation system (Waddell 2002a; Waddell et al. 2003) are being redeveloped within a microsimulation design. The broad class of transportation and land use models that could fall under the title of "microsimulation" began to be developed in the early 1990s, in parallel with major improvements in computational power that allowed for their operation. These included prototype models of activity-based travel, cell-based models land use change, and the introduction of multi-agent models for urban simulation. More recently, some researchers have begun to devote effort to developing comprehensive urban microsimulation models that fully reflect the dynamics of changes in the population and the urban environment within which they make choices.

\section{SPATIAL INTERACTION MODELS}

The earliest class of land use and transportation simulation models are a set of highly aggregate models based on principles of spatial interaction that were popular in the regional science and quantitative geography fields in the 1950s and 1960s. There were many different formulations of this type of model, though most revolved around variations of the gravity model, an adaptation from Newtonian physics. The derivation of the gravity model from principles of entropy maximization (Wilson 1967, 1970) was a major accomplishment and formed the basis for many of the allocation mechanisms within spatial interaction models. A general form of the gravity model can be expressed as:

$$
T_{i j}=A_{i} B_{j} O_{i} D_{j} \exp \left(-\beta c_{i j}\right)
$$

where $T_{i j}$ represents trips (or other measures of interaction) between two zones, $\mathrm{O}_{\mathrm{i}}$ represents origins at zone $i, D_{j}$ represents destinations to zone $j$, and $A_{i}$ and $B_{j}$ are balancing factors to ensure that total origins equal total destinations. The exponential term in the model is used to capture the effect of decreasing interaction as a function of travel cost, including travel time.

As mentioned previously, the first operational land use simulation model was the model developed by Lowry (1964) for the Pittsburgh region. This model has great importance, since many of the other land use and transportation models that follow a spatial interaction framework have similar structures. A detailed review of this model and its variations are provided in Horowitz (2004).

\section{The Lowry Model and Derivatives}

The land use model developed by Lowry was a spatial interaction model designed to simulate patterns of residential and service location in the Pittsburgh, Pennsylvania, region. The impetus for building the model was to be able to simulate the effects of urban renewal and slum clearance programs on the distribution of activities within the region. The model borrowed from economic base theory, which divides a region's employment into basic and nonbasic services. Basic industries are assumed to export much of their product outside the region, generating additional income that can then support additional nonbasic services. Nonbasic industries then serve households (e.g., retail activities) and other industries within the region.

Lowry's model assumed that the location of basic industries was fixed. This required an initial allocation of basic employment to zones within the region. Households were then allocated to zones from the initial basic employment locations, using a function similar to the deterrence function used in the trip 
distribution step of most trip-based travel forecasting models (Horowitz 2004):

$$
f\left(t_{i j}\right)=\exp \left(-\beta t_{i j}\right)
$$

where $f\left(t_{i j}\right)$ is a deterrence function value representing the inverse of the likelihood of workers working in zone $i$ and living in zone $j$, and $t_{i j}$ is a measure of the disutility of travel between zones, typically defined as travel time, and -? represents the marginal disutility per unit of time. This functional form implicitly assumes that workers choose to locate near their workplace and that only one household member is employed outside the home. Lowry chose to define this measure of disutility as the airline distance between zones. He did this partially because of the difficulty of generating matrices of trips between zones using the travel models that existed at the time, but also because he noted a high degree of correlation between observed airline and network distances in his study region (Lowry 1964). Using the deterrence function described above, $f\left(t_{i j}\right)$, the number of workers working in zone $i$ and living in zone $j$ (defined here as $\mathrm{T}_{\mathrm{ij}}$ ) could be calculated by using a modified expression that included a value of attractiveness for each residential zone $\left(\mathrm{w}_{\mathrm{j}}\right)$ :

$$
T_{i j}=\frac{e_{i} w_{j} f\left(t_{i j}\right)}{\sum_{j} w_{j} f\left(t_{i j}\right)}
$$

where $e_{i}$ is the employment in zone $i$. The residential attractiveness measure as used in this formulation simply relates to the amount of land available for residential development in a particular zone. Deleting the variable for zonal employment in the above expression yields an expression for the probability of residing in a zone given a fixed workplace location that is very similar to the probability expression in the multinomial logit model. This relationship is important, since it is used extensively in transportation and land use models that derive from random utility theory, as will be discussed in the next section.

The process of worker/household allocation is followed by a similar process in which the locations of nonbasic industries serving households and other (basic) industries are allocated assuming fixed locations for these quantities. Once these activities have been allocated, it is possible to couple the land use model with a conventional, trip-based travel forecasting model to produce a set of network flows. These new flows and travel times can be used to modify the deterrence function and produce a new allocation of households and nonbasic employment.
Several models extended the basic Lowry framework in new directions. Table 1 lists some of these models along with their distinguishing features. For example, the Time Oriented Metropolitan Model (TOMM) described by Crecine (1964) disaggregated the population into socioeconomic groups to improve the model's representation. It also differed from the Lowry model in that only some of the nonbasic activities in a region would be reallocated between model iterations, reflecting a certain degree of inertia in location. Garin (1966) recast the original Lowry model by proposing a matrix representation for the model's components and substituting a production-constrained, gravity-type interaction model as the basis for allocation. Garin's version also allocated all activities at each iteration, an improvement over Lowry's formulation since it improved the coupling between allocation and generation (Timmermans 2003). Another land use model designed by Goldner (1971) allocated activities according to an intervening opportunity model, a special case of the gravity model (Wilson 1971). The design of the model also sought to improve realism by using different dispersion parameters for each of the nine counties of the San Francisco Bay area, where it was calibrated and tested.

\section{ITLUP/METROPILUS}

Building on the Lowry-Garin framework, Putman (1974, 1983) developed the Integrated Transportation and Land Use Package (ITLUP), widely considered to be the first fully operational transportation-land use modeling software package. ITLUP has been applied in over a dozen locations within the United States, and has been calibrated over forty times (Hunt, Miller, and Kriger 2005). Designed in the mold of the Lowry model, ITLUP initially contained a land use model that was similar to Goldner's PLUM model. ITLUP offered a network representation that allowed for the incorporation of congested travel times in the distribution of activities. At the core of ITLUP were two allocation submodels: a household allocation submodel called DRAM, and an employment allocation submodel, EMPAL. Trip generation and distribution functions for the travel forecasting model are developed within DRAM, simultaneously with household location, while mode choice and trip assignment are handled with separate submodels. Travel times from runs of the travel model are fed forward to calculate new activity distributions.

More recently, the ITLUP model framework has been updated to incorporate modifications to some of its submodels and new data and visualization tools (Putman 2001). The new package, called METROPILUS, 
TABLE 1. Summary of Spatial Interaction / Gravity Models

\begin{tabular}{|c|c|c|}
\hline Model & Reference & Distinguishing Features \\
\hline Model of Metropolis & Lowry (1964); Garin (1966) & $\begin{array}{l}\text { First recognized operational land use model; Garin provided } \\
\text { matrix representation }\end{array}$ \\
\hline TOMM & Crecine (1964) & $\begin{array}{l}\text { Disaggregation of population; incorporation of inertia effects in } \\
\text { activity allocation }\end{array}$ \\
\hline PLUM & Goldner (1971) & $\begin{array}{l}\text { Replaced standard gravity model with intervening opportunity } \\
\text { model; use of county-specific dispersion parameters }\end{array}$ \\
\hline ITLUP & Putman (1983) & $\begin{array}{l}\text { First complete software package for integrated modeling; } \\
\text { improved calibration techniques; improved network model } \\
\text { with multiple modes; incorporation of congestion effects in } \\
\text { activity allocation }\end{array}$ \\
\hline LILT & Mackett (1983) & $\begin{array}{l}\text { Use of accessibility function; car ownership submodel; land use } \\
\text { model capable of handling demolition, changing occupancy } \\
\text { and vacancy rates }\end{array}$ \\
\hline IRPUD & Wegener (1982) & $\begin{array}{l}\text { Contains seven separate submodels; microsimulation of land use; } \\
\text { use of differing spatial scales for submodels; separates } \\
\text { discretionary and non-discretionary travel }\end{array}$ \\
\hline
\end{tabular}

is housed within a geographic information system (GIS) environment that permits improved visualization of output. Other important features of METROPILUS include multivariate, multiparametric attractiveness functions that include lag terms to better capture location dynamics. The addition of zonal constraints can limit allocation of activities to zones where land is not available. Land supply in the model is managed by a land supply function that translates the location demands from employers and households from DRAM and EMPAL into land uses and intensities.

\section{LILT AND IRPUD}

Two other spatial interaction-based models merit attention, since they have been extensively applied and tested. The first is the Leeds Integrated Land Use (LILT) model, developed by Mackett $(1983,1991)$. LILT combines a Lowry-type land use model with a conventional, four-step travel model. Forecasts of change in population are allocated to zones according to accessibility functions derived from work trips and zonal attractiveness functions. Other salient features of LILT include the ability to handle demolition, changing occupancy rates and vacancies, and a car ownership submodel, which estimates vehicle ownership as a function of network travel times and costs (Timmermans 2003).

The IRPUD model (Wegener 1982) was developed by Wegener and colleagues at the University of Dortmund in Germany. IRPUD is quite complex and contains seven interlinked submodels of aging, firm relocation, residential and nonresidential construction, rehabilitation and demolition, change of job, change of residence, and car ownership/travel demand. IRPUD is somewhat unusual in that it contains a microsimulation model of land use, in which land uses are allowed to change through aging. Another desirable feature of IRPUD's design is that it allows different submodels to take place at different spatial scales (intra-regional location takes places at a meso-scopic scale, while land development takes places at a micro/tract level). These features are emulated in some of the newer, emerging urban microsimulation models. As a practical matter, the IRPUD model can be classified along with other spatial interaction models, since it uses gravity models to allocate the distribution of land use.

The first generation of land use and integrated transportation and land use models based on spatial interaction formulations produced a multitude of models that were tested and applied in numerous settings. Some models, such as the METROPILUS planning support system package, continue the legacy of these models to the present. However, very few examples of this type of model framework remain. The shortcomings of these models were numerous: most were static equilibrium models incapable of capturing the dynamics of urban systems; none of the models actually represented land markets with explicit prices; zones were highly aggregate and lacked spatial detail, and the models were inadequately supported by theory. Inadequate theory may have also been a reason that many of the models forecasted so poorly. There were many high-profile failures in terms of using the models for policy analysis purposes (Batty 1979). 
Some of these were seized on by Lee (1973) in a critique that highlighted some of mistakes of the first generation of models. Lee characterized them as being too complicated, overly aggregate, data hungry, wrongheaded, extraordinarily complicated, too mechanical, and expensive. Many of these criticisms informed the next generation of models, which took their cue from developments in econometric modeling based on random utility theory.

\section{ECONOMETRIC APPROACHES}

As noted previously, one of the major shortcomings of the aggregate spatial interaction models was the absence or use of inappropriate theory to describe the behavior captured in the model. Developments in the use of random utility theory to describe choices among discrete alternatives, such as the choice of travel mode, provided the impetus for a new generation of models based on the study of disaggregate behavior. When it was shown that discrete choice models could be applied to problems such as residential location (Lerman 1976; McFadden 1978), researchers began to look for ways to model the interrelated choices individuals made in terms of location and travel behavior.

Land use and transportation models that follow econometric frameworks can be thought of as comprising two types of models: regional economic models and land market models. In these two types of simulation models the economic model and the land market model each form the core of a simulation system that includes the prediction of transportation flows. Both types tend to have improved representation of land markets that include endogenously determined (determined within the model) prices and market clearing mechanisms. A summary of these models and their characteristics are provided in Table 2.

\section{Regional Economic Models}

Two of the most important and widely used transportation and land use models grounded in econometric modeling approaches, MEPLAN and TRANUS, are largely built around a core of a regional economic model. MEPLAN (Echenique et al. 1990; Echenique 2004) is a model that began as a simpler model of urban stock and activity (Echenique, Crowther, and Lindsay 1969) and expanded into a more comprehensive urban simulation model. Similar to other types of models, MEPLAN has a zone-based structure. In contrast to spatial interaction models though, the activities in zones are determined by a spatial input-output model that predicts trade flows by sector between zones of a region, driving the demand for space. Production and consumption are linked in the spatial input-output model, replacing the trip generation and distribution steps in trip-based travel forecasting models. The trade flows are converted to demand for commercial and passenger traffic through the application of scaling constants. The generated traffic is then fed into models of mode and route choice. Congestion and travel times from the transportation model are then fed back into the land use and economic model, yielding time-lagged measures of accessibility, which affect location choice. The structure of MEPLAN, including its spatial economic model, makes it appropriate for modeling not only at an intraurban scale but also at an interurban scale. It has been used in a variety of major applications, including modeling the regional impacts of the Channel Tunnel between England and France (Rohr and Williams 1994).

The TRANUS model (de la Barra 1989) is similar to MEPLAN in that it incorporates a spatial input-output model as the basis of its generation and allocation of activities. The regional economy is disaggregated into sectors, with the demand for each zone and sector generated and then allocated to production zones and sectors via a multinomial logit model. A land supply model is also available to simulate the behavior of developers, who choose where to build (new land versus existing sites), what type of space to build, and at what density. This choice process is governed by explicit prices or rents for new or replacement stock, demolition, and building costs. Another unique feature of TRANUS is its relatively advanced trip-based travel forecasting model. Similar to MEPLAN, flows of traffic between zones are generated from input-output matrices. Personal travel is estimated by time of day by mode as a function of cost. Trips are assigned to the network according to distinct mode-path combinations. Accessibility is calculated as a logsum composite utility measure from the mode choice model and input directly to the land use model to generate a new set of spatial flows.

A third model system that takes as its centerpiece a regional economic model is the PECAS system (Production, Exchange, and Consumption Allocation System), developed by Hunt and Abraham (2005). PECAS is a generalization of the spatial input-output modeling approach used in MEPLAN and TRANUS. The model system is based on a quasi-dynamic equilibrium structure with flows of exchanges, including goods, services, and labor, from production to consumption based on technical coefficients. Flows of exchanges from production to zones of exchange and from exchange zones to consumption are based on nested logit models that take into account exchange prices and transport disutilties. Similar to other spatial input-output models, trade flows are converted to transport demands and loaded onto networks to 
TABLE 2. Summary of Econometric Models

\begin{tabular}{|c|c|c|}
\hline Model & Reference & Distinguishing Features \\
\hline CATLAS & Anas (1982) & $\begin{array}{l}\text { Improved representation of economic agents and decision making; explicit } \\
\text { treatment of housing markets; economic analysis capabilities }\end{array}$ \\
\hline MEPLAN & $\begin{array}{l}\text { Echenique et al. (1969); } \\
\text { Echenique et al. (1990) }\end{array}$ & $\begin{array}{l}\text { Incorporation of spatial input-output model with economic evaluation } \\
\text { component; able to forecast commercial trip generation; travel treated as } \\
\text { a derived demand }\end{array}$ \\
\hline TRANUS & de la Barra (1989) & $\begin{array}{l}\text { Development supply model simulates choices of developers; sophisticated } \\
\text { travel model with combined mode-route choice }\end{array}$ \\
\hline MUSSA & Martinez (1992) & $\begin{array}{l}\text { Incorporation of bid-rent framework for land, floor space markets; detailed } \\
\text { representation of transit network in travel model; high level of household } \\
\text { type disaggregation }\end{array}$ \\
\hline METROSIM & Anas and Arnott (1994) & $\begin{array}{l}\text { Model extended to commercial real estate markets; addition of dynamic } \\
\text { CHPMM housing market model }\end{array}$ \\
\hline NYMTC-LUM & Anas (1998) & $\begin{array}{l}\text { Endogenous determination of housing prices, floor space rents, and wages; } \\
\text { high level of spatial disaggregation suitable for transit and land use policy } \\
\text { evaluation }\end{array}$ \\
\hline DELTA & Simmonds (1999) & $\begin{array}{l}\text { Microsimulation of demographic changes; treatment of quality in the market } \\
\text { for space }\end{array}$ \\
\hline PECAS & Hunt and Abraham (2005) & $\begin{array}{l}\text { Regional econometric model with microsimulation of land development } \\
\text { at the parcel level; ability to couple with an activity-based travel model } \\
\text { and to apply at supra-regional level }\end{array}$ \\
\hline
\end{tabular}

calculate congested travel times (disutilities). Exchange prices for space drive changes in available space, simulating developer actions. The model system is run in one-year time steps, with travel disutilities and changes in space in a given year influencing the flows of exchanges in the next year (Hunt and Abraham 2005).

PECAS now features activity-based travel modules, as well as microsimulations of land development, with land parcels as the unit of analysis. While PECAS is run at the scale of a metropolitan region, it can, like other input-output models, be adapted to larger-scale applications. Recent versions of the model system have been applied in statewide models of land use and transportation for Ohio and Oregon, as well as metropolitan-level applications in Sacramento, CA, and Calgary and Edmonton, Alberta, Canada.

\section{Land Market Models}

Improved land market representation is a distinguishing characteristic of many of the econometric approaches to transportation and land use models. In fact, several them have at their core markets for residential and commercial real estate, with transportation models linked into the overall model structure. Some of these models, such as those developed by Anas $(1982,1984)$, seized on theoretical advances in linking the related strands of gravity-based models with those based on the multinomial logit specification (Williams 1977; Anas 1983).
Anas and colleagues developed a series models (Anas 1982, 1998; Anas and Arnott 1994) designed to simulate the effects of transportation improvements on land markets and overall social welfare. The first such model, CATLAS, emphasizes a discrete choice framework to describe both the supply and demand sides of the housing market. The supply side of the model contains vacancy-occupancy, construction, and demolition submodels that respond to factors such as construction costs, land prices, taxes and operating costs, and expected future resale values. Developers are assumed to be profit maximizers, and so select the location and type of construction to maximize profit. The demand side of the model takes a nested logit choice model form, assuming that households have a fixed workplace location and choose a residential location and travel mode to maximize their utility. Only two workplace locations are considered in the model (CBD and non-CBD), though commuters have a variety of modes available (auto, bus, heavy rail, and commuter rail), depending on their residential location. The model is calibrated with census data and can predict changes in mode splits, house prices and rents, demolitions, and new construction activity (Anas 1987). The economic evaluation component of the model estimates changes in economic welfare because of changes in modal utility arising from investment in different modes. The changes in utility are captured in an inclusive value (logsum) accessibility measure and are capitalized into housing prices or rents. 
The original CATLAS framework was modified in an enhanced model called METROSIM (Anas and Arnott 1994), designed for the New York City metropolitan region. METROSIM incorporated a dynamic model of metropolitan housing markets (Anas and Arnott 1994), along with a model of commercial floor space markets. The full modeling system combined models of employment, residential and commercial real estate, vacant land, households, work and nonwork travel and traffic assignment, which was absent in the CATLAS system. A recent extension of this system is the NYMTC-LUM model (Anas 1998), a simplification of METROSIM designed to facilitate the evaluation of changes in transit policies for the New York City transit system. The model is slightly refined, adding a local labor market submodel and using very small zones to better model transit and auto network flows. The combined model determines housing prices and floor space rents endogenously (within the model), and uses modal utilities from the mode choice model as accessibility inputs to the land use model.

A similar framework was adopted by Simmonds (1999) in developing DELTA, a land use model designed to form the basis of a dynamic model system of land use and transportation interaction. The model system is divided into processes that represent spaces and those that represent activities. Processes dealing with activities include household formation and dissolution, employment growth or decline, location and property markets, and the employment status of individuals. Processes representing the change in spaces predict the quantity and quality of floor space available. The model system is designed to be run over a series of short steps of no more than one or two years, and was originally coupled with START, a transportation model developed for the city of Leeds, United Kingdom. A distinguishing feature of DELTA is attempts to add a quality variable to the prediction of location choices. In the case of residential location, the quality variable relates to local income and vacancy rates. Hence, the quality of development can change over time. The DELTA model has seen several applications in the United Kingdom and parts of Western Europe and is currently being developed as a microsimulation model system.

An alternative framework for modeling land markets in transportation and land use models was provided by Martinez (1992, 1996), who built an integrated model called MUSSA for the city of Santiago, Chile. MUSSA adopted a modified version of the "bid-rent" framework for land markets, first articulated by Ellickson (1981). The "bid-choice" framework used by Martinez combines bid-rent and discrete choice approaches to land markets by dealing simultaneously with both sides of an auction in a bi-level framework. The MUSSA system provides an equilibrium model of building stock supply and demand, where buyers maximize their surplus, sellers maximize price, and builders maximize profits. Building stock prices are then endogenously determined in the model.

The MUSSA system also includes a rather sophisticated four-step travel forecasting model that is linked to the land use component. The travel model features a detailed transit network representation and the ability to forecast demand for eleven separate alternatives, including road, transit, and mixed modes. The combined transportation and land use models are referred to as 5-LUT (indicating a five-step forecasting procedure), and are able to provide equilibrated forecasts of land use and travel demand. A notable feature of MUSSA is that the model uses smaller-than-average zones as units of analysis to achieve a higher level of spatial disaggregation. Likewise, there is an effort to disaggregate the treatment of households within the model, with the Santiago application containing sixtyfive different household types. This is an important step in the development of transportation and land use models, and one that is being replicated in the current generation of transportation and land use models based on microsimulation techniques, as will be discussed in the following section.

Another transportation and land use simulation model that adopts this highly disaggregate structure is the UrbanSim model developed by Waddell and colleagues (Waddell 2000, 2002a). Like MUSSA, UrbanSim is primarily a model of land markets, though extensions have been considered to add an activity-based travel forecasting model (Waddell 2002b), as well as an environmental analysis module (Waddell and Borning 2004). Like MUSSA, UrbanSim initially contained a highly disaggregated household treatment, with 111 distinct household types identified in an early calibration of the model (Waddell 2000). Demographic transition in population and household formation are microsimulated within a separate submodel. Residential mobility of households is characterized by a two-stage process in which households decide whether to search and then whether to move. Location choice of households and firms are represented by a multinomial logit model considering all zones in the region within the choice set. While UrbanSim makes extensive use of econometric models in its structure, predictions are based on Monte Carlo simulation methods, indicating that it also has the characteristics of a microsimulation model system.

UrbanSim's structure is also unusual in that it operates in disequilibrium from year to year, with no 
general equilibrium in land markets assumed at the end of a time step, though market clearing does occur at the transportation analysis zone (TAZ) level. This feature sets it apart from the preceding models that incorporate land markets, which are typically static within each time step of a simulation. Researchers in the field of urban modeling have previously commented on the importance of modeling different elements of urban systems at the time scales in which they operate (Wegener 1994; Miller 2003). Since urban areas do not really ever reach a general equilibrium in land and travel markets, this disequilibrium structure will likely be adopted in many future attempts to model land markets.

UrbanSim's model of land markets also estimates supply at the parcel level, using parcel databases within a GIS. Demand for housing and floor space are calculated at the TAZ level in the original version of the model, though subsequent versions are attempting to reconcile the spatial scale of the supply-demand relationship. Land markets are simulated using the bid-choice framework, similar to the MUSSA model (Waddell 2000). Land prices are estimated from hedonic regressions containing building unit and neighborhood characteristics, and regional accessibility to work and shopping. The neighborhood characteristics are determined by partitioning the region into 150-by-150 meter grid cells, each containing information about neighborhood composition and nearby land uses.

Further work on UrbanSim is focusing on converting it to a comprehensive microsimulation modeling system (Waddell et al. 2003). Many of the elements of the original model loaned themselves to this treatment, including the high level of household type disaggregation and demographic transition submodel. The land market simulation is already highly disaggregated and requires only further refinement of developer behavior. The structure of the model system suggests that modified transportation submodels, such as an activity-based travel model, could be coupled with the other elements in the model system. Long-term goals of the project include developing the software architecture to support an agent-based simulation version of the modeling system and the exploration of new model structures.

The experience with the generation of transportation and land use models based on econometric frameworks has been valuable and addressed one of the most pointed criticisms of the previous generation of spatial interaction models, that of lack of theory. The use of random utility theory and advancements in discrete choice modeling of individual behavior have allowed for the inclusion of economic evaluation components in several of the models, as well as improved accessibility measures based on utility functions. Also, the introduction of model systems built around a regional economic model allowed for the inclusion of commercial travel in forecasts and the general treatment of travel as a derived demand. Despite these advancements, many of the econometric models retained a number of problems left over from the previous generation of models. For example, most of the models remained highly aggregate, despite the use of disaggregate calibration methods. This became one source of bias in the model forecasts. Also, with the exception of UrbanSim, all of the models were essentially static in nature. Their structure forced them to reach a general equilibrium between each time step in the model; this was especially true of the models focusing on land markets. Furthermore, little advancement was made in the transportation component of the model. Most models continued to use trip-based, four-step forecasting procedures, where all submodels except mode choice were run at an aggregate level. Much of the current research into microsimulation methods is attempting to address this issue, along with other pressing research questions in the design of comprehensive simulation models of transportation and land use.

\section{DISAGGREGATE AND MICROSIMULATION MODELS}

Since the late 1980s, advances in computing power and efficiency of data storage have allowed researchers to begin to build models that address many of the shortcomings associated with previous large-scale modeling efforts and represent important change processes in cities with the detail they require. Examples of these include activity-based models of travel behavior, multiagent models of urban land use and transportation, and cell-based models of urban land use. The common conceptual underpinning of each of these models is that they attempt to represent processes of change from the bottom up, that is, they account for the behavior of individual agents in space and/or time, along with interactions between agents. The use of the term microsimulation can be applied to each of these types of models, though it requires some definition. As defined by Miller (2003), microsimulation relates to "a method or approach (rather than a model per se) for exercising a disaggregate model over time." All of the types of models identified above are what would be considered disaggregate models and all have a significant temporal element. Microsimulation methods are particularly effective for modeling systems that are dynamic and complex, which urban systems invariably are. 


\section{Activity-Based Travel Models ${ }^{2}$}

Research into the foundations of travel behavior dating back to the 1970s has identified many shortcomings in the use of sequential, trip-based traveldemand forecasting models (Hagerstrand 1970; Chapin 1974). However, there was little incentive until this time to attempt to recast travel forecasting procedures. Oil crises during the 1970s precipitated research into various energy use reduction strategies, including demand management measures and transportation system management techniques. It was then that the inability of existing forecasting models, which were mostly static and aggregate, to predict behavioral responses to such policy measures became apparent (McNally 2000).

A combination of factors brought about resurgence in interest in reconceptualizing travel behavior for modeling purposes during the 1990s. The completion of the interstate system and the difficulty of expanding existing urban road networks led many regional planning organizations to emphasize preservation and management of transportation systems through such policies as flexible working hours, travel information provision, traffic flow improvements, and diversion of some travel to alternate modes. The potential changes in travel behavior implied by these policies cannot be forecast using existing methods, since trip-based models separate travel decisions from their broader context of activity participation and temporal constraints. At the same time, improvements in computing power and the use of geographic information systems have allowed for the formalization and testing of models that previously existed only at conceptual or limited empirical levels. Support from the Federal Highway Administration in the form of the Travel Model Improvement Program (TMIP), which attempted to improve the state of practice in transportation modeling and facilitate development of a new generation of travel demand models, has also had a significant impact.

The first demonstration of an operational model of activity-based travel preceded the TMIP, and was conducted by Recker, McNally, and Root (1986a, 1986b). The STARCHILD model was developed to investigate dynamic ridesharing, but was designed for research purposes only and required collection of data that is still not commonly available (McNally 2000). Models of activity chains and travel behavior were coupled with a mesoscopic traffic simulation in work by Axhausen (1990). Pendyala et al. (1997) developed an activity-based simulation model capable of predicting activity scheduling changes in response to transportation control measures. They demonstrated their model with an application to evaluate the impacts of control measures in the Washington, D.C., metropolitan region. Activity-based forecasting models incorporating GIS applications have also been developed by McNally (1998). Bowman and Ben-Akiva (2001) structured a model of activity participation within a nested logit framework to predict travel tours (clusters of chained trips). Their model was calibrated using travel survey data from the Boston region. A model system developed by Arentze and Timmermans (2004) attempted to simulate learning behavior by agents within the context of activity scheduling and travel behavior. Perhaps the most ambitious effort to date in the United States has been the research program associated with the TRANSIMS modeling system, which is designed to combine an activity-based forecasting model with a region-wide traffic microsimulation system (Barrett 1995).

Activity-based models are necessarily disaggregate and attempt to simulate travel behavior within the limits of time and space. Because of spatial and temporal interdependencies, this process cannot be modeled within a framework that treats trips as independent and generates trips at an aggregate level. An alternative, agent-based approach is typically adopted in formal travel forecasting applications. This focus on the behavior of individual agents and addition of temporal elements makes activitybased travel models a natural complement to microsimulation models of transportation and land use that focus on the activity of agents at an individual or household level.

\section{Agent-Based Microsimulation Models}

The state-of-the art in transportation and land use modeling is defined by current research efforts aimed at building comprehensive microsimulation systems of urban areas, with representation at the level of individual agents (persons, households, firms, etc.) and simulations of the behavior of the entire population of interest. The advantages of adopting such a modeling approach for urban systems are many (Miller 2003):

- Urban systems are dynamic, with a significant time element and components changing at different speeds.

- The behaviors of these systems are complex, with interacting agents, complex decision-making processes, and significant probabilistic elements.

- Closed-form mathematical and statistical representations of urban systems often introduce large amounts of bias and lead to poor forecasts.

The seeds of comprehensive microsimulation models had been sown in a number of earlier models, 
TABLE 3. Summary of Microsimulation Models of Transportation and Land Use

\begin{tabular}{|c|c|c|}
\hline Model & Reference & Distinguishing Features \\
\hline ILUTE & Salvani and Miller (2005) & $\begin{array}{l}\text { Comprehensive urban system microsimulation model; structured to accurately } \\
\text { capture temporal elements urban change; activity-travel model includes } \\
\text { household member interactions; disequilibrium modeling framework }\end{array}$ \\
\hline ILUMASS & $\begin{array}{l}\text { Moeckel et al. (2003); } \\
\text { Strauch et al. (2003) }\end{array}$ & $\begin{array}{l}\text { Descendent of IRPUD model; incorporates microscopic dynamic simulation } \\
\text { model of traffic flows and goods movement model; designed with environmental } \\
\text { evaluation submodel; }\end{array}$ \\
\hline Ramblas & Veldhuisen et al. (2000) & Entirely rule-based model framework; designed to simulate very large populations \\
\hline UrbanSim & Waddell et al. (2003) & $\begin{array}{l}\text { Land use model incorporating microsimulations of demographic processes land } \\
\text { use development; parcel-level land use representation; high level of household } \\
\text { type disaggregation; open-source software developed for general use }\end{array}$ \\
\hline
\end{tabular}

where one or more elements of the system were governed by a microsimluation process. For example, Wegener's IRPUD model contained microsimulations of population and building stock. Mackett's (1990) MASTER model simulated location choices and travel decisions, and MUSSA and UrbanSim disaggregated households at a level sufficient to operate them in a static microsimulation format, where a representative sample is used within a microanalytic framework for short-run applications. However, for long-term forecasts, which most transportation and land use models are designed for, the population must be synthesized or updated to represent the dynamics of individuals and the environments within which they make choices.

An overview of some of the comprehensive microsimulation systems currently under development are presented in Table 3. The UrbanSim system was the only simulation model to transition from a static simulation format to a dynamic microsimuation model. As noted previously, the original version of UrbanSim contained a number of microsimulation submodels within its structure, thus eliminating the need for as radical a redesign as would be needed for many of the static, equilibrium models.

The ILUMASS simulation system (Moeckel et al. 2003; Strauch et al. 2003), being developed by a research team at the University of Dortmund, builds on the experience of Wegener and others with the IRPUD model in the 1980s. The design of ILUMASS embeds a microscopic dynamic simulation model of urban traffic flows within a comprehensive model system incorporating changes in land use and building stock.

The microsimulation modules of ILUMASS include models of demographic change, household formation, firm lifecycles, residential and nonresidential construction, labor mobility in a regional labor market, and residential mobility in a regional housing market. These modules are linked with models of daily activity participation and travel, as well as goods movement. The activity-travel module uses data collected via a hand-held survey instrument. This innovation in data collection allows for near-real-time information on activity and travel behavior, obviating the need for respondents to recall their activities later on. The GIS component of ILUMASS combines raster-based and vector-based representations, allowing for the advantages of spatial disaggregation in land use representation and efficient network algorithms for the transportation network model.

The ILUTE model (Salvani and Miller 2005), being developed by researchers at a number of Canadian universities, chiefly the University of Toronto, represents the most complete microsimulation model to date. The product of a long-term effort to design an "ideal" simulation model of transportation and land use, ILUTE centers around a behavioral core consisting of four interrelated components: land use, location choice, auto ownership, and activity/travel patterns. The model system is highly integrated with feedback mechanisms whereby higher-level (longer-term) decisions, such as residential mobility, affect lower-level (shorter-term) decisions, such as activity participation and travel. ILUTE is not based on a single modeling technique (e.g., random utility), but rather uses a variety of modeling approaches to represent the behavior of agents in the model, such as state transition models, random utility models, computational rule-based models, learning models, and hybrids of previous approaches.

ILUTE's treatment of land markets explicitly assumes a constant disequilibrium framework, indicating that a particular house could be on the market for several months without selling, since no market clearing is assumed. The time steps in the model are brought down to the level of months, rather than years, to provide greater temporal detail. The disequilibrium 
framework and absence of market clearing also means that projects with extended construction periods (e.g., greater than one year) can be accommodated. The housing market submodel within ILUTE assumes a three-step process to describe residential mobility, involving a mobility decision, a search process, and bidding and search termination.

The transportation component of ILUTE is quite sophisticated and includes submodels for automobile transactions and activity scheduling. The activity scheduling submodels characterizes activities as occurring in time and space, with various scheduling dependencies to represent temporal constraints (Roorda, Doherty, and Miller 2005). Future plans include adding a network model, which is needed to provide travel times and costs by mode, along with a formal model of activity participation. Like most comprehensive microsimulation models, ILUTE is still in the process of calibrating some of the submodels in the system, and has yet to be used in a full forecasting application, though the travel demand component has been applied in a policy simulation (Roorda and Miller 2006).

Another agent-based simulation model that merits attention is the Ramblas model (Veldhuisen, Timmermans, and Kapoen 2000, 2005). While it is not as comprehensive as the other models described here, Ramblas is designed to simulate the effects of land use and transportation planning policies, with an emphasis on the prediction of activity participation and traffic flows. An unusual aspect of Ramblas is that it is designed to simulate the effects of policies on the entire Dutch population (estimation at more than sixteen million). The model also distinguishes itself by being entirely rule-based, rather than adopting a formal theoretical framework to guide the behavior of agents. These aspects of the model derive from its stated purpose of being a practical planning tool to assess the impact of various transportation and land use scenarios.

Ramblas is run by selecting households, stratified according to size and structure. Individuals are classified according to one of twenty-four population segments, defined on the basis of age, gender, education, and employment status. An activity agenda and transportation mode are drawn at random, with seven activity types available. Destinations are randomly drawn from a choice set, sometimes delimited by a given action space or distance constraint. Origindestination pairs are generated from the activity and mode allocations and traffic flows are then microsimulated, calculating travel times via a speed-flow method. Output from the microsimulation of traffic is used to forecast changes in land use, dwelling stock, and road construction.

\section{Cellular Models}

The representation of land use in integrated models of transportation and land use change has been one of the less satisfactory elements of these models (Chang 2006). Until recently, land use had generally been represented by zones that served as convenient areal units for the location of activities, and coincided with zonal designations for transportation models. Models that provide greater simplicity and a clearer representation of the dynamics of land use change using cell-based representations of regions have emerged within the past two decades as an increasingly attractive land use modeling alternative.

Cell-based models, and particularly those based on cellular automata (CA) theory, arise from the application of complexity theory to cities (Batty 1997, 2005). Complexity theory conceptualizes systems, such as urban systems, as being too complex to synthesize using closed-form, predetermined mathematical representation. Rather, these systems arise from the collective interaction and self-organization of large numbers of individual agents that generate the observed macro-level states (Benenson 1998). Cellbased models of land use can range from simple state transition models in which cells change states (land uses) according to some observed probability, to the more general form of CA, in which cell states are also a function of states in neighboring cells. CA models can be seen as extension of agent-based microsimulation models, in which individual cells are the agents, rather than persons or households.

CA models generally require four basic elements: a lattice of regular spaces or cells, a set of allowed states, neighborhoods that are defined by the lattice, and a set of transition rules governing the evolution of individual cells in the system. Many CA models also add a fifth, temporal element. CA models are basically deterministic, rule-based models, using "if-then-else" logical statements to build their transition rules, though stochastic elements can be added to transition rules using probabilistic expressions and random number generation. Other types of modifications to CA models intended to introduce complexity include changes to the structure and dimension of the lattice of cells, expansion of allowable cell states, expanded neighborhood definitions to include action at a distance, and changes to temporal elements, such as Markov chains (Torrens and O'Sullivan 2001).

A precursor to many of the contemporary cellular models being used to describe the dynamics of urban systems is the model of self-forming neighborhoods presented by Schelling (1978). As part of a larger exposition of self-organizing principles, Schelling 
demonstrated how "individually motivated" forms of segregation could arise through the interaction of many agents (households) pursuing their own objectives. Preferences for individuals of a different race, income, or any other form of social stratification were shown to lead to highly segregated outcomes under a variety of initial conditions and preference structures.

The compatibility of CA models with GIS, remote sensing data, and associated visualization capabilities make them particularly suitable for land use modeling applications (Torrens and O'Sullivan 2001). It is here that they have received the most attention. One example is the model of urban land use developed by Clarke, Hoppen, and Gaydos (1997) to estimate the regional impact of urbanization on the San Francisco Bay Area's climate. This model is an example of a selfmodifying CA, in which the CA can adapt to the circumstances it generates. Clarke and Gaydos (1998) applied the same model to the Baltimore-Washington region to generate long-term urban growth predictions. Jantz, Goetz, and Shelley (2004) also studied growth in the Baltimore-Washington region using CA, with the objective of simulating the effects of different patterns of land use on the Chesapeake Bay watershed. Levinson and Chen (2005) describe the development of a Markov Chain model of land use change for the Minneapolis-St. Paul region. Their model adopts the discrete-time version of a Markov Chain and predicts the evolution of transportation networks and land use patterns over the period from 1958 to 1990 . A next step for this model would be to add neighbor effects, which would move it to a CA-Markov Chain framework.

Other applications of CA include simulating land use density conditions, as in the model developed by Yeh and Li (2002). Their model incorporates a density gradient in the simulation of urban development for different urban forms. The transition rules of their model specify a density, obtained from a distancedecay function, to be applied to cells as they are converted to developed cells. Kii and Doi (2005) provide a similar application to demonstrate the effects of compact city form and mixed land use on total trip length, energy consumption, and social welfare in Takamatsu, Japan. The model they present, MALUT, is a multiagent model of transportation and land use, where a CA model of land use is coupled with a microsimulation model of travel. Accessibility can be incorporated into a CA model of land use change, as demonstrated by Ottensmann's (2005) LUCI2 model. LUCI2 was designed to predict employment and land conversion change over a forty-four-county region of Central Indiana, consisting of eight separate metropolitan statistical areas. The model found access to employment to be an important determinant of residential development and density.

CA models appear to be growing more complex. Their many applications reflect the relative ease and flexibility with which they can be modified to describe processes of change. CA models are not without their weaknesses, though. Their simplicity, which is one of their most desirable attributes, is also a significant limitation. In most cases, they are inappropriate for modeling systems with complex interactions. For example, processes such as land development represent the interaction between human and physical systems, but CA models cannot capture both. Also, CA models are not designed to be forecasting tools. Since they are calibrated on historical data and lack a strong behavioral interpretation, most forecasts have little meaning. Rather, CA are better suited to idealized principles of cities and urban design applications than large-scale simulations or strategic planning (Batty 1997).

\section{RESOLVED AND ONGOING MODELING ISSUES}

\section{Old Issues}

The models currently being developed to describe change in transportation and land use systems look very different than those that existed a few decades ago. One might question then to what extent these newer models have overcome the deficiencies of earlier generations of models, such as the criticisms lodged against the first generation of spatial interaction-based simulation models.

Reflecting on the earlier experience, some modelers claimed in the early 1990s that advances in computer processing power and data storage would obviate many of the problems identified by Lee (1973) in his critique of the early modeling experience (Harris 1994). While these advances have undoubtedly reduced some of the costs of building, operating, and maintaining transportation and land use models, concomitant expansions in the scope of these models, as exemplified by the current generation of urban micrsosimulation models, ensures they will continue to be a resource-intensive effort. These models also remain highly complex, with many interacting submodels. Calibration is still a daunting task, even for models that are available as commercial packages. Data requirements are still large, especially for dynamic models that require synthesis of a population or continual updating of a sample.

It must also be recognized though, that a number of problems identified with earlier models have been, at least partially, resolved. Most microsimulation models are no longer static, and can simulate changes 
in transportation network performance and land use through time. Nearly all models now are able to model land markets with explicit prices and the ability to simulate the behavior of various agents in the land development process. The level of aggregation of agents is being reduced, especially in comprehensive microsimulation models. The size of zones in most models is now much smaller, and should continue to decrease as computing power permits, though spatial detail in many models could certainly improve. Perhaps most importantly, the theoretical basis of models has improved, especially in ongoing efforts to reconceptualize the relationship between individual activity patterns and travel choices for travel demand forecasting.

\section{New Directions}

The development of advanced models of transportation and land use change brings about opportunities for exploring some important topics related to the models themselves and their representation of real-world urban regions. The following are some issues worthy of more attention.

\section{The Use of Theory}

Some researchers question the continuing use of broad theoretical frameworks to guide agent behavior in model systems. Timmermans (2003) points to the use of random utility theory to describe a wide range of spatial choices in many models. Noting that utility is a concept that must be built up over several repetitive choice situations, he questions the applicability of this concept to rare decisions such as mobility and residential location. Also, it is questionable whether discrete choice methods and random utility theory are applicable to entities such as firms, which comprise collective choice situations, as opposed to individual agents. Models like Ramblas and ILUTE, which use rule-based or hybrid modeling approaches, suggest that tailoring the right tool to each model component can overcome this issue. Timmermans also noted that most models are consumers of theory rather than producers, indicating that model development ought to coincide with the process of theory development.

\section{Forecast Accuracy}

Recent studies that have sought to explore the propagation of uncertainty through transportation and land use models (Pradhan and Kockelman 2002; Krishnamurthy and Kockelman 2003; Clay and Johnston 2006) have identified a continuing trend of large variation in output from these models. Presumably, the addition of better model dynamics and disaggregation of population groups within microsimulation models will reduce some of the bias present in earlier, more aggregate models. However, long-term forecasting models of many types necessarily retain significant amounts of irreducible uncertainty, and the lack of available forecasting results from applications of newer models leaves some room for concern.

\section{Treatment of Supply Side}

In most forecasting applications the supply side of transportation, as represented by the extent and capacity of networks, is held fixed or treated as a policy variable. The limited available evidence on the evolution of networks over time (Yamins, Rasmussen, and Fogel 2003; Yerra and Levinson 2005; Levinson and Yerra 2006; Zhang and Levinson 2007) suggests that scenarios such as alternative ownership regimes and their impact on transportation-land use systems are a topic worthy of exploration with more comprehensive models.

\section{Agglomeration Effects}

Previous reviews of operational models of transportation and land use (Berechman and Small 1988) identified the absence of agglomerative effects as a major weakness of the land use component of these models. Recent work using multi-agent systems (Arentze and Timmermans 2003) suggests that modeling this effect is possible, and it is deserving of further exploration.

\section{Person-Based Accessibility}

Since accessibility is still seen as an important component of location choice in transportation and land use models, especially for residential location, it makes sense to pursue measures of accessibility that recognize the importance of treating travel behavior as a process constrained in time and space, as is reflected in activitybased travel models. Examples have been provided in work by Kwan and Weber (2003) and Miller (2005).

Future work in these key areas holds some promise to improve the validity of land use and transportation models. Many of the suggested actions can be, and in some cases have been, incorporated into existing models. Recent versions of UrbanSim have attempted to simulate agglomeration effects by including a variable in the utility expression for firm location choice reflecting the existence of employment in the same industry. As a proxy for agglomeration effects, this feature should improve location choice models by providing a complement to traditional accessibility measures as determinants of employment location.

Incorporation of person-based accessibility measures also seems feasible, and has been demonstrated 
by Dong et al. (2006) in an application of activity-based accessibility using an activity-based travel modeling system developed by Bowman and Ben-Akiva (2001). While this approach represents a definite improvement to the modeling of travel demand, it is unclear whether the use of activity-based measures of accessibility will greatly affect longer-term location decisions as currently structured within land use models.

Explicit treatment of the supply side in transportation models would also improve their capacity to reflect the dynamics of land use and network growth. In a previous application, Levinson and Karamalaputi (2003) demonstrated how factors such as existing traffic demand, demographic characteristics, and present network conditions could be used to predict network expansion. Incorporation of a separate submodel within current operational models seems a viable and useful alternative to treating the supply side of transportation systems as fixed.

Perhaps the most important line of inquiry for future work in land use and transportation modeling relates to understanding the accuracy and level of uncertainty inherent in existing and proposed operational models. As indicated, some of this work has already begun. Future work may continue to use simulation methods, such as Monte Carlo or Latin Hypercube sampling (Hess, Train, and Polak 2006) to relate changes in inputs and model parameters to various model outputs. The outcome of this line of work will provide important feedback to model users about the acceptability of forecasts based on current operational model systems.

\section{CONCLUSION}

Models of transportation and land use change have evolved significantly since their early applications more than four decades ago. In the search to design models that capture the recursive relationship between transportation and land use, there has been a general trend toward the disaggregation of the representation of people and space. Newer models represent in greater detail the dynamics of the transportation-land use change process. Experiments with bottom-up approaches to modeling urban systems, especially those that recognize the interactions between agents, provide an alternative means for understanding their complexity. Yet, the ability to forecast these processes for policy applications remains an important goal. Most of the newer generations of microsimulation models are designed with the objective of making them more policy sensitive. Unfortunately, few of them have yet reached a point where they can be fairly evaluated on this criterion, and the older operational models still raise important questions about the utility of such complex tools.

One must be more circumspect, though, in evaluating the transportation and land use modeling experience more generally. In reflecting on the experience with the first generation of models nearly three decades ago, Batty (1979) noted that models should be evaluated in terms of their contribution to both science and design (i.e., policy). Many of the earliest models were failures on both accounts, though there has arguably been some success on the science side since then.

Models continue to represent an important means of testing theories and developing knowledge about the behavior of urban systems. For example, land use and transportation models have emphasized the role of accessibility in location choices from their earliest origins. They have provided a method for formally and quantitatively understanding this link and its effects on urban structure. Another contribution that modeling efforts have made has been to treat cities as living, dynamic systems. While virtually all operational models include some type of feedback effect, the increasing inclusion of dynamic effects in the form of lagged responses to transportation network or land use changes has increased the realism and applicability of many models. Furthermore, recent modeling efforts are beginning to incorporate principles of selforganization in representing urban growth and change. Agent-based and microsimulation models demonstrate the importance of individual action, as opposed to top-down decision-making, in representing dynamics of urban growth and change. Recent microsimulation models such as UrbanSim have been able to capture unique spatial effects, such as neighborhood effects, in residential location choices. Agglomeration effects in firm location choice have also been added to reflect concentrations of an industry type in specific locations.

Another observation by Batty related to the status of planning as a science. He argued that planning was (at the time) an "immature" science, marked by poor theoretical development, continuing controversy about methods and results, and the tendency to follow "fashions." In many respects this is true of the field today, as in the continuing controversy over the influence of land use patterns on travel behavior. Batty suggested that this status may be inherent to planning, which is considered a "policy" science, and hence subject to the dictates of short-term policy needs, albeit at the expense of long-term theory development. This trend continues to the present and will likely do so in the future, as the needs for policy-oriented analysis (design) work continue to dominate planning practice. Batty noted though, that periodic reflection and critical 
review by those engaged in research can be seen as a sign of maturity. There has been much of this in the field of transportation and land use modeling, as in the related field of travel demand analysis (see, for example Pas 1990). Continued reflection and a commitment to developing models that reflect the relevant theoretical constructs of the behavior or system being studied are seen then as the most promising paths toward developing transportation and land use modeling toward a more "mature" state and building more practically useful tools.

\section{NOTES}

1. Reviews that cover a larger number of models, including some that have seen less commercial application, are provided in recent articles by Timmermans (2003) and Wegener (1994, 2004). Chang (2006) also provides a review of models based on mathematical programming formulations, which are not discussed here.

2. The literature on activity-based approaches to travel analysis is quite extensive and dates to the 1970s. Thus, a comprehensive review of this literature is not possible here. Instead, the focus will be on covering a few of the models that have been tested using real-world data at least once. The interested reader is directed to articles by Axhausen and Garling (1992), Ettema and Timmermans (1997), McNally (2000), Vovsha, Bradley, and Bowman (2005), and the collection of articles in the August 1996 issue of the journal Transportation, which describes the early results of research work funded through TMIP.

\section{REFERENCES}

Anas, Alex. 1982. Residential location markets and urban transportation: Economic theory, econometrics and policy analysis with discrete choice models. New York: Academic Press.

—. 1983. Discrete choice theory, information theory and the multinomial logit and gravity models. Transportation Research, Part B 17B(1): 13-23.

- 1984. Discrete choice theory and the general equilibrium of employment, housing and travel networks in a Lowry-type model of the urban economy. Environment E Planning A 16(11): 1489-1502.

- 1987. Modeling in urban and regional economics. Chur, Switzerland: Harwood Academic Publishers.

- 1998. NYMTC transportation models and data initiative. The NYMTC Land Use Model. Williamsville, NY: Alex Anas \& Associates.

Anas, Alex, and Richard J. Arnott. 1994. The Chicago prototype housing market model, with tenure choice and its policy implications. Journal of Housing Research 5:73-129.

Arentze, Theo A., and Harry J. P. Timmermans. 2003. Modeling agglomeration forces in urban dynamics: A multi-agent system approach. Paper presented at the 8th International Conference on Computers in Urban Planning and Urban Management, May 27-29, Sendai, Japan.

- 2004. A learning-based transportation-oriented simulation system. Transportation Research, Part B: Methodological 38B(7): 613-33.

Axhausen, Kay W. 1990. A simultaneous simulation of activity chains and traffic flow. In Developments in dynamic and activitybased approaches to travel analysis, ed. Peter M. Jones, 206-25. Brookfield, VT: Avebury.

Axhausen, Kay W., and Tommy Garling. 1992. Activity-based approaches to travel analysis: Conceptual frameworks, models and research problems. Transport Reviews 12(4): 323-341.
Barrett, C. 1995. An operational description of TRANSIMS (No. LA-UR95-2393). Los Alamos, NM: Los Alamos National Laboratory.

Batty, Michael. 1979. Progress, success and failure in urban modeling. Environment \& Planning A 11(8): 863-878.

1997. Cellular automata and urban form: A primer. Journal of the American Planning Association 63(3): 264-274.

- 2005. Cities and complexity: Understanding cities with cellular automata, agent-based models and fractals. Cambridge, MA: MIT Press.

Benenson, Itzhak. 1998. Multi-agent simulations of residential dynamics in the city. Computers, Environment and Urban Systems 22(1): 25-42.

Berechman, Joseph, and Kenneth A. Small. 1988. Modeling land use and transportation: An interpretive review for growth areas. Environment \& Planning A 20(10): 1285-1309.

Bowman, John L., and Moshe E. Ben-Akiva. 2001. Activity-based disaggregate travel demand model system with activity schedules. Transportation Research, Part A: Policy and Practice 35A(1): 1-28.

Cervero, Robert. 1984. Light rail transit and urban development. Journal of the American Planning Association 50(2): 133-147.

Chang, Justin. 2006. Models of the relationship between transport and land-use: A review. Transport Reviews 26(3): 325-50.

Chapin, F. Stuart. 1974. Human activity patterns in the city. New York: Wiley.

Clarke, K. C., and L. Gaydos. 1998. Loose-coupling a cellular automaton model and GIS: Long-term urban growth prediction for San Francisco and Washington/Baltimore. International Journal of Geographic Information Science 12:699-714.

Clarke, K. C., S. Hoppen, and L. Gaydos. 1997. A self-modifying cellular automaton model of historical urbanization in the San Francisco Bay area. Environment \& Planning B: Planning and Design 24(2): 247-61.

Clay, Michael J., and Robert A. Johnston. 2006. Multivariate uncertainty analysis of an integrated land use and transportation model: MEPLAN. Transportation Research, Part D: Transport and Environment 11D(3): 191-203.

Crecine, J. P. 1964. TOMM. Pittsburgh: Department of City and Regional Planning.

de la Barra, Tomas. 1989. Integrated transport and land use modeling: Decision chains and hierarchies. Cambridge, UK: Cambridge University Press.

Dong, Xiaojing, Moshe E. Ben-Akiva, John L. Bowman, and Joan L. Walker. 2006. Moving from trip-based to activity-based measures of accessibility. Transportation Research, Part A: Policy and Practice 40(2): 163-80.

Echenique, Marical H. 2004. Econometric models of land use and transportation. In Handbook of transport geography and spatial systems, ed. David A. Hensher, Kenneth J. Button, Kingsley E. Haynes, and Peter R. Stopher, 185-202. Amsterdam: Pergamon.

Echenique, Marcial H., D. Crowther, and W. Lindsay. 1969. A spatial model of urban stock and activity. Regional Studies 3:281-312.

Echenique, Marcial H., A. D. Flowerdew, J. D. Hunt, T. R. Mayo, I. J. Skidmore, and D. C. Simmonds. 1990. The Meplan models of Bilbao, Leeds and Dortmund. Transport Reviews 10(4): 309-22.

Ellickson, B. 1981. An alternative test of the hedonic theory of housing markets. Journal of Urban Economics 9(1): 56-79.

Ettema, Dick, and Harry J. P. Timmermans. 1997. Activity-based approaches: An introduction. In Activity-based approaches to travel analysis, ed. Dick Ettema and Harry J.P. Timmermans, 1-36. Oxford, UK: Pergamon.

Garin, Robert A. 1966. A matrix formulation of the Lowry model for intra-metropolitan activity. Journal of the American Institute of Planners 32:361-64.

Goldner, W. 1971. The Lowry model heritage. Journal of the American Institute of Planners 37:100-10. 
Hagerstrand, Torsten. 1970. What about people in regional science? Papers of the Regional Science Association 24:7-21.

Harris, Britton. 1994. The real issues behind Lee's "Requiem." Journal of the American Planning Association 60(1): 31-34.

Hess, Stephane, Kenneth E. Train, and John W. Polak. 2006. On the use of a Modified Latin Hypercube Sampling (MLHS) method in the estimation of a Mixed Logit Model for vehicle choice. Transportation Research, Part B: Methodological 40B(2): 147-63.

Horowitz, Alan J. 2004. Lowry-type land use models. In Handbook of transport geography and spatial systems, ed. David A. Hensher, Kenneth J. Button, Kingsley E. Haynes, and Peter R. Stopher, 16783. Amsterdam: Pergamon.

Hunt, John D., and John E. Abraham. 2005. Design and implementation of PECAS: A generalised system for allocating economic production, exchange and consumption quantities. In Integrated land-use and transportation models: Behavioural foundations, ed. Martin Lee-Gosselin and Sean Doherty, 253-73. Amsterdam: Elsevier.

Hunt, John D., Eric J. Miller, and David S. Kriger. 2005. Current operational urban land-use-transport modelling frameworks: A review. Transport Reviews 25(3): 329-76.

Jantz, Claire A., Scott J. Goetz, and Mary K. Shelley. 2004. Using the SLEUTH urban growth model to simulate the impacts of future policy scenarios on urban land in the Baltimore/Washington metropolitan area. Environment \& Planning B: Planning and Design 31(2): 251-71.

Kelly, Eric D. 1994. The transportation land-use link. Journal of Planning Literature 9(2): 128-45.

Kii, Masanobu, and Kenji Doi. 2005. Multiagent land-use and transport model for the policy evaluation of a compact city. Environment E Planning B: Planning and Design 32(4): 485-504.

Krishnamurthy, Sriram, and Kara M. Kockelman. 2003. Propagation of uncertainty in transportation land use models: Investigation of DRAM/EMPAL and UTPP predictions in Austin, Texas. Transportation Research Record 1831:219-29.

Kwan, Mei-Po, and Joe Weber. 2003. Individual accessibility revisited: Implications for geographical analysis in the twenty-first century. Geographical Analysis 35:341-53.

Lee, Douglass B. 1973. Requiem for large scale urban models. Journal of the American Institute of Planners 39(2): 163-78.

Lerman, Steven R. 1976. Location, housing, automobile ownership and mode to work: A joint choice model. Transportation Research Record 610:6-11.

Levinson, David M., and Wei Chen. 2005. Paving new ground: A Markov Chain model of the change in transportation networks and land use. In Access to destinations, ed. David M. Levinson and Kevin J. Krizek, 243-66. Amsterdam: Elsevier Science Publishers.

Levinson, David M., and Ramachandra Karamalaputi. 2003. Induced supply: A model of highway network expansion at the microscopic level. Journal of Transport Economics and Policy 37(3): 297-318.

Levinson, David M., and Bhanu Yerra. 2006. Self-organization of surface transportation networks. Transportation Science 40(2): 179-88.

Lowry, Ira S. 1964. A model of metropolis. Santa Monica, CA: Rand Corporation.

Mackett, Roger L. 1983. The Leeds integrated land-use transport model (LILT). Crowthorne, UK: Transport and Road Research Laboratory.

- 1990. Exploratory analysis of long-term travel demand and policy impacts using micro-analytical simulation. In Developments in dynamic and activity-based approaches to travel analysis, ed. Peter M. Jones, 384-405. Brookfield, VT: Avebury.

. 1991. LILT and MEPLAN: A comparative analysis of land-use and transport policies for Leeds. Transport Reviews 11(2): 131-54.
Martinez, Francisco J. 1992. The bid-choice land use model: an integrated economic framework. Environment \& Planning A 24: 871-85.

_. 1996. MUSSA: A land-use model for Santiago city. Transportation Research Record 1552:126-34.

McFadden, Daniel L. 1978. Modelling the choice of residential location. In Spatial interaction theory and planning models, ed. Anders Karlqvist, 75-96. Amsterdam: North-Holland.

McNally, Michael G. 1998. Activity-based forecasting models integrating GIS. Geographical Systems 5(2): 163-184.

- 2000. The activity-based approach. In Handbook of transport modeling, ed. David A. Hensher and Kenneth J. Button, 53-69. Amsterdam: Pergamon.

Miller, Eric J. 2003. Microsimulation. In Transportation systems planning: Methods and applications, ed. Konstadinos G. Goulias, 12.1-12.22. Boca Raton, FL: CRC Press.

Miller, Harvey J. 2005. Place-based versus people-based accessibility. In Access to destinations ed. David M. Levinson and Kevin J. Krizek, 63-89. Amsterdam: Elsevier.

Moeckel, R., K. Spiekermann, C. Schurmann, and M. Wegener. 2003. Microsimulation of land use, transport and environment. Paper presented at the 8th International Conference on Computers in Urban Planning and Urban Management, May 27-29, Sendai, Japan.

Ottensmann, John R. 2005. Accessibility in the Luci2 Urban Simulation model and the importance of accessibility for urban development. In Access to destinations, ed. David M. Levinson and Kevin J. Krizek, 297-324. Amsterdam: Elsevier.

Pas, Eric I. 1990. Is travel analysis and modelling in the doldrums? In Developments in dynamic and activity-based approaches to travel analysis, ed. Peter M. Jones, 3-33. Brookfield, VT: Avebury.

Pendyala, Ram M., Ryuichi Kitamura, Cynthia Chen, and Eric I. Pas. 1997. An activity-based microsimulation analysis of transportation control measures. Transport Policy 4(3): 183-92.

Pradhan, Anant, and Kara M. Kockelman. 2002. Uncertainty propagation in an integrated land use-transportation modeling framework: Output variation via UrbanSim. Transportation Research Record 1805:128-35.

Putman, Stephen H. 1974. Preliminary results from an integrated transportation and land use models package. Transportation 3(3): 193-224.

- 1983. Integrated urban models: Policy analysis of transportation and land use. London: Pion.

. 2001. The METROPILUS planning support system: Urban models and GIS. In Planning support systems: Integrating geographic information systems, models and visualization tools, ed. Richard K. Brail and Richard E. Klosterman, 99-128. Redlands, CA: ESRI Press.

Recker, Wilfred W., Michael G. McNally, and Gregory S. Root. 1986a. A model of complex travel behavior (I): Theoretical development. Transportation Research, Part A 20A(4): 307-18.

1986b. A model of complex travel behavior (II): An operational model. Transportation Research, Part A 20A(4): 319-30.

Rohr, C., and I. N. Williams. 1994. Modelling the regional economic impacts of the Channel Tunnel. Environment \& Planning B: Planning and Design 21: 555-568.

Roorda, Matthew J., Sean T. Doherty, and Eric J. Miller. 2005. Operationalising household activity scheduling models: Addressing assumptions and the use new sources of behavioural data. In Integrated land-use and transportation models: Behavioural foundations, ed. Martin Lee-Gosselin and Sean T. Doherty, 61-85. Amsterdam: Elsevier.

Roorda, Matthew J., and Eric J. Miller. 2006. Assessing transportation policy using an activity-based microsimulation model of travel demand. ITE Journal 76(11): 16-21.

Ryan, Sherry. 1999. Property values and transportation facilities: Finding the transportation-land use connection. Journal of Planning Literature 13(4): 412-27. 
Salvani, Paul, and Eric J. Miller. 2005. ILUTE: An operational prototype of a comprehensive microsimulation model of urban systems. Networks and Spatial Economics 5(2): 217-34.

Schelling, Thomas C. 1978. Micromotives and macrobehavior. New York: Norton.

Simmonds, David. 1999. The design of the DELTA land-use modelling package. Environment $\mathcal{E}$ Planning B: Planning and Design 26:665-84.

Strauch, D., R. Moeckel, M. Wegener, J. Grafe, H. Muhlhans, G. Rindsfuser, and K.-J. Beckmann. 2003. Linking transport and land use planning: The microscopic dynamic simulation model. Paper presented at the 7th International Conference on Geocomputation, Sept. 8-10, Southampton, UK.

Timmermans, Harry J. P. 2003. The saga of integrated land usetransport modeling: How many dreams before we wake up? Paper presented at the 10th International Conference on Travel Behaviour Research, Aug. 10-15, Lucerne, Switzerland.

Torrens, Paul M., and David O'Sullivan. 2001. Cellular automata and urban simulation: Where do we go from here? Environment E Planning B: Planning and Design 28(2): 163-68.

Veldhuisen, K. Jan, Harry J. P. Timmermans, and Loek L. Kapoen. 2000. Ramblas: A regional planning model based on the microsimulation of daily travel patterns. Environment \& Planning $A$ 32(3): 427-443.

- 2005. Simulating the effects of urban development on activity-travel patterns: An application of Ramblas to the Randstad North Wing. Environment \& Planning B: Planning and Design 32(4): 567-80.

Vovsha, Peter, Mark A. Bradley, and John L. Bowman. 2005. Activitybased travel forecasting models in the United States: Progress since 1995 and prospects for the future. In Progress in activitybased analysis, ed, Harry J. P. Timmermans, 389-414. Amsterdam: Elsevier.

Waddell, Paul A. 2000. A behavioral simulation model for metropolitan policy analysis and planning: Residential location and housing market components of UrbanSim. Environment \& Planning B: Planning and Design 27(2): 247-63.

. 2002a. UrbanSim, modeling urban development for land use, transportation and environmental planning. Journal of the American Planning Association 68:297-314. 2002b. Design of an integrated land use and activity-based travel model system for the Puget Sound region. Transportation Research Record 1805:108-18.

Waddell, Paul A., and Alan Borning. 2004. A case study in digital government: Developing and applying UrbanSim, a system for simulating urban land use, transportation, and environmental impacts. Social Science Computer Review 22(1): 37-51.

Waddell, Paul A., A. Borning, M. Noth, N. Freier, M. Becke, and G. Ulfarsson. 2003. Microsimulation of urban development and location choices: Design and implementation of UrbanSim. Networks and Spatial Economics 3(1): 43-67.

Wegener, Michael. 1982. Modeling urban decline: A multi-level economic-demographic model of the Dortmund region. International Regional Science Review 7(1): 21-41.

1994. Operational urban models: State of the art. Journal of the American Planning Association 60(1): 17-30.

- 2004. Overview of land use transport models. In Handbook of transport geography and spatial systems, ed. David A. Hensher, Kenneth J. Button, Kingsley E. Haynes, and Peter R. Stopher, 12746. Amsterdam: Pergamon.

Williams, Huw C. W. L. 1977. On the formation of travel demand models and economic evaluation measures of user benefit. Environment \& Planning A 9(3): 285-344.

Wilson, Alan G. 1967. A statistical theory of spatial distribution models. Transportation Research 1: 253-269.

. 1970. Entropy in urban and regional modelling. London: Pion.

. 1971. A family of spatial interaction models, and associated developments. Environment \& Planning 3(1): 1-32.

Yamins, Daniel, Steen Rasmussen, and David Fogel. 2003. Growing urban roads. Networks and Spatial Economics 3(1): 69-85.

Yeh, Anthony G., and X. Li. 2002. A cellular automata model to simulate development density for urban planning. Environment $\mathcal{E}$ Planning B: Planning and Design 29:431-50.

Yerra, Bhanu, and David M. Levinson. 2005. The emergence of hierarchy in transportation networks. Annals of Regional Science 39(3): 541-53.

Zhang, Lei, and David M. Levinson. 2007. The economics of transportation network growth. In Essays on transport economics, ed. P. Coto and V. Inglada, 317-40. Heidelberg: Physica-Verlag. 